\title{
NOTES
}

\section{Synthesis of Sequential Polyamide by Direct Polycondensation II.}

\author{
Mitsuru Ueda, Makoto Morishima, and Mayumi KaKuTA \\ Department of Materials Science and Engineering, Faculty of Engineering, \\ Yamagata University, Yonezawa, Yamagata 992, Japan
}

(Received June 14, 1991)

\begin{abstract}
KEY WORDS Sequential Polyamide / Direct Polycondensation / Activating Agent / Nonsymmetric Diamine / Dicarboxylic Acid /
\end{abstract}

As part of our research program on the synthesis of condensation polymers by a direct polycondensation, ${ }^{1}$ our group have recently initiated the synthesis of sequential polyamide by the direct polycondensation.

In the preceding paper, ${ }^{2}$ we reported a method for the synthesis of sequential polyamide (head-to-head, or tail-to-tail). This polymer was prepared by the direct polycondensation of symmetric monomer (YccY), isophthalic acid with nonsymmetric monomer (XabX), 2,6-dimethyl-p-phenylenediamine using the activating agent, diphenyl(2,3dihydro-2-thioxo-3-benzoxazolyl)phosphate (1).

In our continuing investigation of versatility of this method, we now report a successful synthesis of sequential (head-to-head or tail-to-tail) polyamide by the direct polycondensation of isophthalic acid (2b) with 2-(4-aminophenyl)ethylamine (5) using the activating agent $\mathbf{1}$.

\section{EXPERIMENTAL}

\section{Materials}

$\mathrm{N}$-Methyl-2-pyrrolidone (NMP) was purified by vacuum distillation and stored over 4-A molecular sieves. Benzoic acid (2a) and isophthalic acid (2b) were purified by recrystallization. 2-(4-aminophenyl)ethylamine (5) was purified by vacuum distilation $\left(116^{\circ} \mathrm{C} /\right.$
$1 \mathrm{mmHg}$ ). Triethylamine (TEA) was purified by a usual method. Other reagents and solvents were obtained commertially and used as received.

The activating agent diphenyl(2,3-dihydro2-thioxo-3-benzoxazolyl)phosphate (1) was prepared according to the reported procedure. ${ }^{3}$

$N, N^{\prime}$-Di(2-phenylethyl)isophthalamide (4). The activating agent $1(0.422 \mathrm{~g}, 1.1 \mathrm{mmol})$ was added to a solution of $\mathbf{2 b}(0.0831 \mathrm{~g}, 0.5 \mathrm{mmol})$ and TEA $(0.14 \mathrm{ml})$ in NMP $(1.0 \mathrm{ml})$ at room temperature. After $10 \mathrm{~min}, 2$-phenylethylamine (3) $(0.121 \mathrm{~g}, 1 \mathrm{mmol})$ was added. Stirring of the mixture was continued for $1 \mathrm{~h}$, and poured into $10 \%$ aqueous sodium hydrogen carbonate. The precipitate was filtered, washed with water, and dried. The yield was $0.182 \mathrm{~g}(98 \%)$. Recrystallization from aqueous methanol afforded white leaflets. $\mathrm{mp} 172-172^{\circ} \mathrm{C}$. IR $(\mathrm{KBr}): v$ $3290(\mathrm{~N}-\mathrm{H}), 1640 \mathrm{~cm}^{-1}(\mathrm{C}=\mathrm{O}) .{ }^{13} \mathrm{C}$ NMR $\left[\left(\mathrm{CD}_{3}\right)_{2} \mathrm{SO}\right]: 165.5 \mathrm{ppm}(\mathrm{C}=\mathrm{O})$. Anal. Calcd for $\mathrm{C}_{24} \mathrm{H}_{24} \mathrm{~N}_{2} \mathrm{O}_{2}$ : C, 77.39\%; $\mathrm{H}, 7.52 \% ; \mathrm{N}$, $6.50 \%$. Found: C, $77.24 \% ; \mathrm{H}, 7.49 \%$; , $6.58 \%$.

2-[4-( $N$ '-Benzoylamino $)$ phenyl $]-N$-benzoylethylamine (6). This compound was prepared from $5(0.068 \mathrm{~g}, 0.5 \mathrm{mmol})$ and $2 \mathrm{a}(0.122 \mathrm{~g}$, $1 \mathrm{mmol}$ ) as described above. The yield was $0.159 \mathrm{~g}(93 \%)$. Recrystallization from methanol yielded white crystals. $\mathrm{mp} 226^{\circ} \mathrm{C}$ (by DTA) (lit. $\left.{ }^{4} 223^{\circ} \mathrm{C}\right)$. IR (KBr): $v 3230 \quad(\mathrm{~N}-\mathrm{H})$, $1640 \mathrm{~cm}^{-1}(\mathrm{C}=\mathrm{O}) .{ }^{13} \mathrm{C} \mathrm{NMR}\left[\left(\mathrm{CD}_{3}\right)_{2} \mathrm{SO}\right]$ : 
165.9, $165.1 \mathrm{ppm}(\mathrm{C}=\mathrm{O})$.

$N$-Phenyl- $N^{\prime}$-(2-phenylethyl)isophthalamide (9). The activating agent $1(0.422 \mathrm{~g}, 1.1 \mathrm{mmol})$ was added to a solution of 3-carboxybenzanilide $8(0.243 \mathrm{~g}, 1 \mathrm{mmol}), 3(0.121 \mathrm{~g}$, $1 \mathrm{mmol})$, and TEA $(0.14 \mathrm{ml}, 1 \mathrm{mmol})$ in NMP $(1.0 \mathrm{ml})$ at room temperature. The solution was stirred for $1 \mathrm{~h}$ at this temperature. The product was isolated as described above. The yield was $0.170 \mathrm{~g}(99 \%)$. Recrystallization from aqueous methanol yielded white leaflets. $\mathrm{mp} 185$ $186^{\circ} \mathrm{C}$. IR $(\mathrm{KBr}): v 3320(\mathrm{~N}-\mathrm{H}), 1650 \mathrm{~cm}^{-1}$ $(\mathrm{C}=\mathrm{O}) .{ }^{13} \mathrm{C} \mathrm{NMR}\left[\left(\mathrm{CD}_{3}\right)_{2} \mathrm{SO}\right]: 165.4,164.8$ ppm $(\mathrm{C}=\mathrm{O})$. Anal. Calcd for $\mathrm{C}_{22} \mathrm{H}_{20} \mathrm{~N}_{2} \mathrm{O}_{2}: \mathrm{C}$, $76.72 \%$; H, 5.85\%; N, 8.13\%. Found: C, $76.77 \% ; \mathrm{H}, 6.01 \% ; \mathrm{N}, 7.96 \%$.

\section{POLYMER SYNTHESIS}

\section{Authentic Polyamide (11)}

$N, N^{\prime}$-Di[2-(4-aminophenyl)ethyl]isophthalamide (10). A solution of $1(0.805 \mathrm{~g}, 2.1 \mathrm{mmol})$, 2b $(0.166 \mathrm{~g}, 1 \mathrm{mmol})$, and TEA $(0.28 \mathrm{ml}$, $2 \mathrm{mmol})$ in NMP $(1.0 \mathrm{ml})$ was added dropwise at room temperature with stirring to a solution of $5(0.272 \mathrm{~g}, 2 \mathrm{mmol})$ in NMP $(0.5 \mathrm{ml})$. The addition was completed in $30 \mathrm{~min}$, and stirring of the mixture was continued for an additional $1 \mathrm{~h}$. The solution was poured into $10 \%$ aqueous sodium hydrogen carbonate $(100 \mathrm{ml})$. A precipitate formed, and it was collected by filtration, washed with water, and dried in vacuo. The yield was $0.362 \mathrm{~g}(90 \%)$. Recrystallization from benzonitrile produced white crystals. mp $154-157^{\circ} \mathrm{C}$. IR $(\mathrm{KBr}): v$ $3300(\mathrm{~N}-\mathrm{H}), 1640 \mathrm{~cm}^{-1}(\mathrm{C}=\mathrm{O})$. Anal. Calcd for $\mathrm{C}_{24} \mathrm{H}_{20} \mathrm{~N}_{4} \mathrm{O}_{2}: \mathrm{C}, 71.62 \% ; \mathrm{H}, 6.51 \% ; \mathrm{N}$, $13.92 \%$. Found: C, $71.63 \% ; \mathrm{H}, 6.43 \%$; , $13.70 \%$.

The activating agent $1(0.422 \mathrm{~g}, 1.1 \mathrm{mmol})$ was added to a solution of $10(0.202 \mathrm{~g}$, $0.5 \mathrm{mmol}), \quad 2 \mathrm{~b} \quad(0.0831 \mathrm{~g}, \quad 0.5 \mathrm{mmol}), \quad \mathrm{LiCl}$ $(0.0013 \mathrm{~g}, \quad 0.03 \mathrm{mmol})$, and TEA $(0.14 \mathrm{ml}$, $1 \mathrm{mmol}$ ) in NMP (1 ml). The mixture was stirred for $24 \mathrm{~h}$ at room temperature. The resulting viscous solution was diluted with
NMP $(2-3 \mathrm{ml})$ and poured into methanol $(200 \mathrm{ml})$. The polymer that precipitated was filtered and was refluxed in methanol for $2 \mathrm{~h}$. The polymer was collected and dried in vacuo at $80^{\circ} \mathrm{C}$. The yield was $0.266 \mathrm{~g}(100 \%)$. The inherent viscosity of the polymer in NMP was $0.32 \mathrm{dlg}^{-1}$ at a concentration of $0.5 \mathrm{~g} \mathrm{dl}^{-1}$ at $30^{\circ} \mathrm{C}$. IR $(\mathrm{KBr}): v 3240(\mathrm{~N}-\mathrm{H}), 1640 \mathrm{~cm}^{-1}$ $(\mathrm{C}=\mathrm{O})$. Anal. Calcd for $\left(\mathrm{C}_{16} \mathrm{H}_{14} \mathrm{~N}_{2} \mathrm{O}_{2} \cdot 1 / 2\right.$ $\left.\mathrm{H}_{2} \mathrm{O}\right)_{n}$ : C, $69.74 \% ; \mathrm{H}, 5.49 \% ; \mathrm{N}, 10.18 \%$. Found: C, $70.59 \%$; H, 5.32\%; N, 9.81\%.

Random Polyamide (12) from Isophthaloyl Chloride and 5. A solution of $5(0.136 \mathrm{~g}$, $1 \mathrm{mmol})$ and TEA $(0.28 \mathrm{ml}, 2 \mathrm{mmol})$ in NMP $(0.5 \mathrm{ml})$ was cooled to a mush with a dry ice-acetone bath. To this was added a solution of isophthaloyl chloride $(0.203 \mathrm{~g}, 1 \mathrm{mmol})$ in NMP ( $1 \mathrm{ml})$ in one portion, and the cooling bath was changed to an ice-water bath. The mixture was stirred for $24 \mathrm{~h}$. The polymer was isolated as described above. A $96 \%$ yield of the polymer having an inherent viscosity of $0.34 \mathrm{dlg}^{-1}$ in $\operatorname{NMP}\left(\mathrm{C}=0.5 \mathrm{~g} \mathrm{dl}^{-1}\right.$ at $\left.30^{\circ} \mathrm{C}\right)$ was obtained. IR $(\mathrm{KBr}): \quad v 3250(\mathrm{~N}-\mathrm{H}), 1650 \mathrm{~cm}^{-1}(\mathrm{C}=\mathrm{O})$. Anal. Calcd for $\left(\mathrm{C}_{16} \mathrm{H}_{14} \mathrm{~N}_{2} \mathrm{O}_{2} \cdot 1 / 2 \mathrm{H}_{2} \mathrm{O}\right)_{n}$ : C, $69.74 \%$; H, $5.49 \%$; N, $10.18 \%$. Found: C, $69.53 \%$; H, 5.37\%; N. 9.89\%.

Polyamide $\mathbf{1 3}$ from $\mathbf{2 b}$ and $\mathbf{5}$. To a solution of $5(0.136 \mathrm{~g}, 1 \mathrm{mmol})$ in NMP $(0.5 \mathrm{ml})$ was added dropwise at room temperature a solution of $2 \mathbf{b}(0.166 \mathrm{~g}, 1 \mathrm{mmol})$, TEA $(0.28 \mathrm{ml}, 2 \mathrm{mmol})$, and $1(0.805 \mathrm{~g}, 2.1 \mathrm{mmol})$ in NMP $(1 \mathrm{ml})$. The addition was $30 \mathrm{~min}$, and stirring of the mixture was continued for $24 \mathrm{~h}$. The polymer was isolated as described above. The yield was $0.270 \mathrm{~g}(100 \%)$. The inherent viscosity was $0.30 \mathrm{dl} \mathrm{g}^{-1}$ in NMP $\left(\mathrm{C}=0.5 \mathrm{~g} \mathrm{dl}^{-1}\right.$ at $\left.30^{\circ} \mathrm{C}\right)$. IR $(\mathrm{KBr}): \quad v 3240(\mathrm{~N}-\mathrm{H}), 1650 \mathrm{~cm}^{-1} \quad(\mathrm{C}=\mathrm{O})$. Anal. Calcd for $\left(\mathrm{C}_{16} \mathrm{H}_{14} \mathrm{~N}_{2} \mathrm{O}_{2} \cdot 1 / 2 \mathrm{H}_{2} \mathrm{O}\right)_{n}$ : C, $69.74 \%$; H, 5.49\%; N, $10.18 \%$. Found: C, $69.99 \% ; \mathrm{H}, 5.39 \% ; \mathrm{N}, 9.67 \%$.

\section{RESULTS AND DISCUSSION}

\section{Model Reaction}

The synthesis of sequential polyamide 
(head-to-head or tail-to-tail) from XabX and YccY monomers requires that the ratio of rate constants for the reactions of functional groups of nonsymmetric monomer XabX, $r=k_{\mathrm{bx}} / k_{\mathrm{ax}}$ should be small. In the previous paper, ${ }^{5}$ we measured the overall second order rate constant $(k)$ for the reaction of $\mathbf{2 a}$ with various anilines in NMP in the presence of $\mathbf{1}$, and found that there is a linear relationship with a slope of 1 between $\log k$ and $\mathrm{p} K_{\mathrm{a}}$ of aniline derivatives. As the difference of $\mathrm{p} K_{\mathrm{a}}$ values between an aliphatic amine and an aromatic amine is about 5 , the rate constants for the aminolysis of the active intermediate will be changed by more than $10^{5}$ when the amine is varied from the aliphatic amine to the aromatic amine. Thus, 2-(4-aminophenyl)ethylamine (5) was chosen as the XabX monomer for the polycondensation.

Prior to the synthesis of sequential polyamides, the following model compound work was performed by the direct procedure to determine if the model compounds were formed in quantitative yields to constitute a polymer-forming reaction. This procedure consists of the addition of $\mathbf{1}$ to a solution of a carboxylic acid and an amine in NMP that contains a tertiary organic base to form a carboxylate anion.

The reaction of isophthalic acid $\mathbf{2 b}$ with 2-phenylethylamine 3 and that of benzoic acid 2a with 2-(4-aminophenyl)ethylamine 5 were studied (eq 1 and 2).

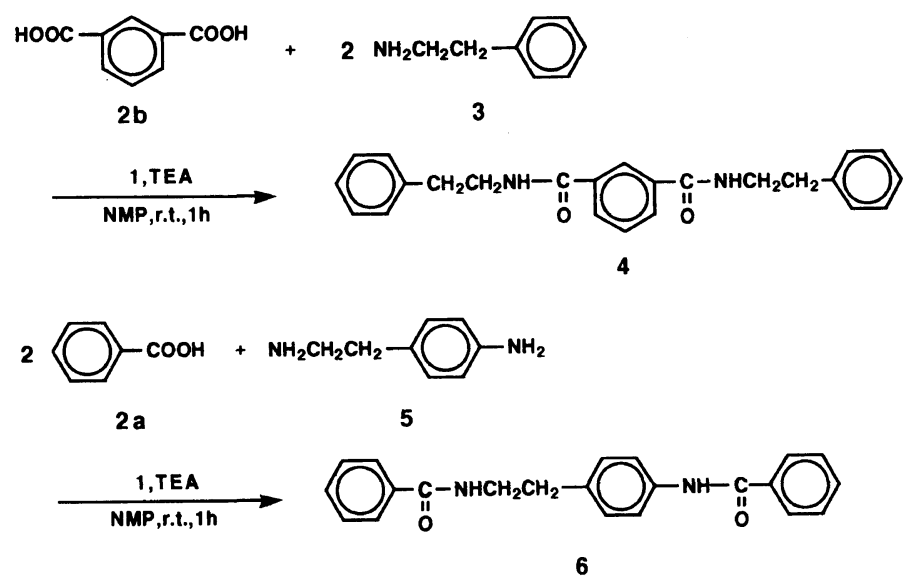

The reactions afforded the model compounds, $N, N^{\prime}$-di(2-phenylethyl)isophthalamide (4) and 2-[4-( $N^{\prime}$-benzoylamino)phenyl]- $N$-benzoylethylamine (6) in quantitative yields.

To clarify the structure of sequential polyamides, the following model compound
$N$-phenyl- $N^{\prime}$-(2-phenylethyl)isophthalamide (9) was also prepared from 3 and 3-carboxybenzanilide (8) which was obtained by alkaline hydrolysis of 3-methoxycarbonylbenzanilide (7) (eq 3).

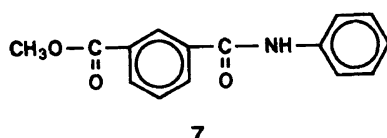

7

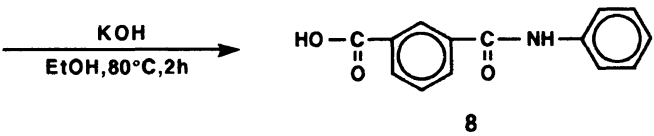

8

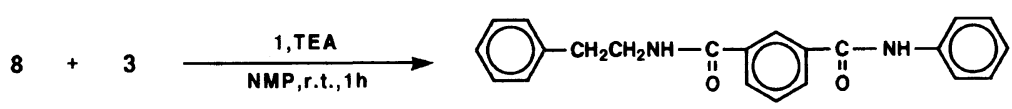




\section{Polymer Synthesis}

Synthesis of Authentic Polyamides. The authentic polyamides, such as head-to-head or tail-to-tail and random polyamides were synthesized for characterization of the structure of sequential polyamides obtained by the direct polycondensation.
The authentic polyamide (11), as head-tohead or tail-to-tail polyamide was prepared by the direct polycondensation of $\mathbf{2 b}$ with $N, N^{\prime}$-di[2-(4-aminophenyl)ethyl]isophthalamide (10) which was obtained from $\mathbf{2 b}$ and 5 (eq 4).

$$
2 \mathrm{~b}+5 \frac{1, \mathrm{TEA}}{\mathrm{NMP, \text {r.t., } \mathrm { h }} \longrightarrow}
$$

The polycondensation proceeded smoothly and gave the polyamide $\mathbf{1 1}$ with inherent viscosity of $0.32 \mathrm{dl} \mathrm{g}^{-1}$.

The random polyamide 12 was synthesized

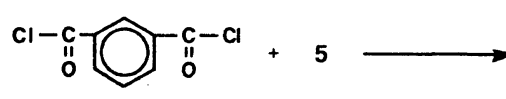

Synthesis of Sequential Polyamide (head-tohead, or tail-to-tail) 13. As described in the preceding paper, ${ }^{2}$ if $\mathrm{XabX}$ monomer is mixed all at once with YccY monomer, where we have arbitrary chosen -aX to be the faster reacting group $(r \ll 1)$, only random polymer can be obtained. To obtain the head-to-head or tail-to-tail polymer, YccY should be added slowly to XabX, that is, if YccY is added slowly to $\mathrm{XabX}$ so that there will never be any unreacted -cY groups. After half of the YccY is added, the only XbaccabX will be produced. Upon addition of the rest of YccY, only -bccb- structures will be formed. Accordingly, the resulting polymer will contain -acca- and -bccb- arrangements only, and the probability of two adjacent nonsysmmetric units in a chain from isophthaloyl chloride and $\mathbf{5}$ by the low temperature solution polymerization. Polycondensation was carried out in NMP by mixing both monomers all at once (eq 5).

Random Polyamide 12

The direct polycondensation of $\mathbf{2 b}$ with $\mathbf{5}$ in the presence of $\mathbf{1}$ was carried out at room temperature by the slow addition of $\mathbf{2 b}$ to $\mathbf{5}$, and gave polyamide $\mathbf{1 3}$ with inherent viscosity of $0.30 \mathrm{dl} \mathrm{g}^{-1}$.

\section{Polymer Characterization}

The polymer 13 was defined as the expected sequential polyamide by comparing its IR spectrum with those of model compounds. The IR spectrum exhibited characteristic absorption at 3300 due to the NH streching and two strong absorptions at 1640 and $1540 \mathrm{~cm}^{-1}$, which are assigned to amide I and amide II bands. Elemetal analyses also supported the formation of the expected polymer. 
The microstructure of polymer was de- The ${ }^{13} \mathrm{C}$ spectra of polyamide 13 and random termined by means of ${ }^{13} \mathrm{C}$ NMR spectroscopy.

${ }^{13} \mathrm{C}$ NMR chemical shifts of amide carbonyl groups for model compounds are shown in Scheme 1.

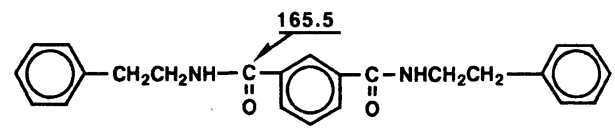
polyamide 12 are presented in Figures 1 and 2 , respectively. The spectrum of polyamide $\mathbf{1 3}$ was identical to that of polyamide 11. The resonances with $\mathrm{CO}$ chemical shifts in the amides between 164.5 and $165.5 \mathrm{ppm}$, are assigned, as shown in the inset in Figure 1, on the basis of assignments for the model compounds.

On the other hand, the four peaks of carbon<smiles>O=C(Nc1ccccc1)c1cccc(C(=O)Nc2ccccc2)c1</smiles><smiles>CC(C)(C)C(=O)c1cccc(C(C)(C)CCCc2ccccc2)c1</smiles><smiles>CC(C)(C(=O)NCCc1ccc(NC(=O)c2ccccc2)cc1)C(=O)c1ccccc1</smiles>

Scheme 1. nuclei in amide carbonyl groups for polyamide 12 were observed at 165.5, 165.4, 164.6, and $164.5 \mathrm{ppm}$ (Figure 2) as would be expected from its random structure.

These results clearly indicate that the direct polycondensation of $\mathbf{2} \mathbf{b}$ with $\mathbf{5}$ produced the desired head-to-head or tail-to-tail $(\mathrm{s} \simeq 0)$ polyamide.

The polyamides were white solids, soluble in sulfuric acid, methanesulfonic acid, and dipolar aprotic solvents, such as NMP, DMF, and

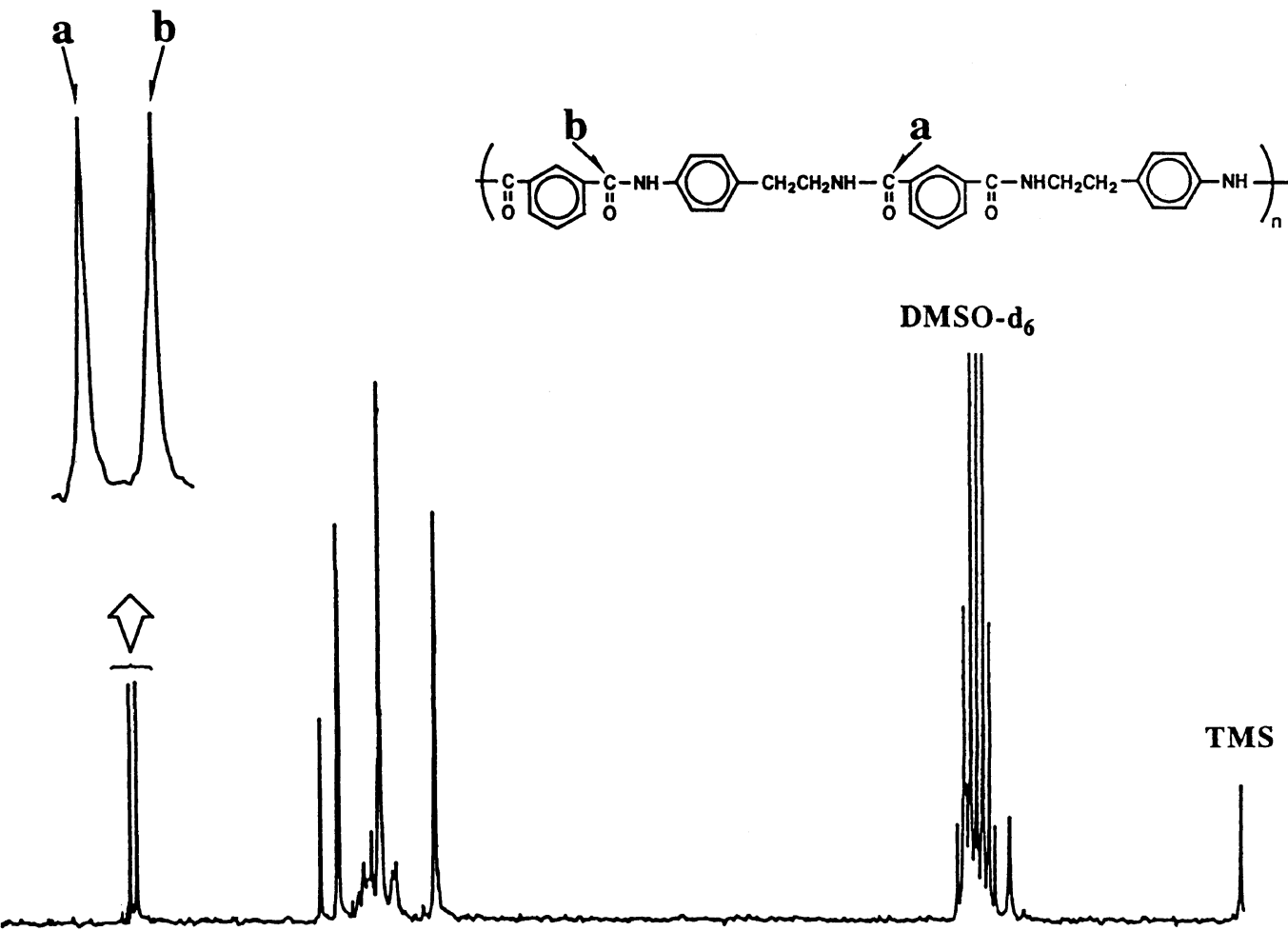

Figure 1. ${ }^{13} \mathrm{C}$ NMR spectra of polyamide 13 in $\left[\left(\mathrm{CD}_{3}\right)_{3} \mathrm{SO}\right]$ at $25^{\circ} \mathrm{C}$. 


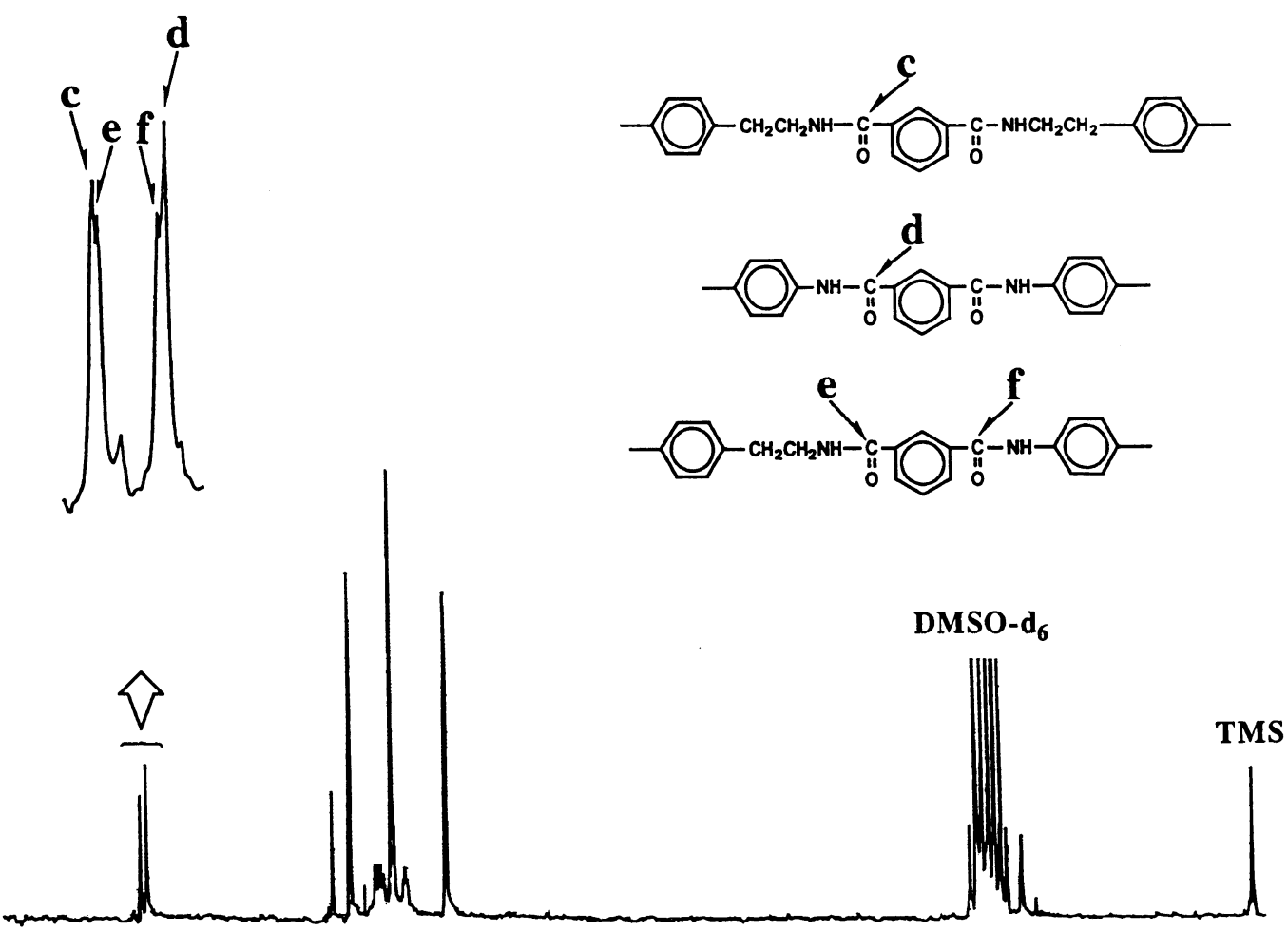

Figure 2. ${ }^{13} \mathrm{C}$ NMR spectra of polyamide 12 in $\left[\left(\mathrm{CD}_{3}\right)_{3} \mathrm{SO}\right]$ at $25^{\circ} \mathrm{C}$.

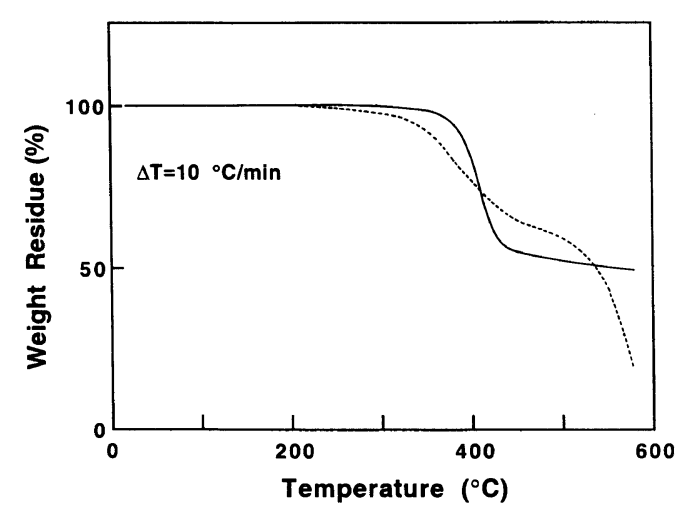

Figure 3. TG curves of polyamide 13 in nitrogen $(-)$ and in air (----).

\section{DMSO.}

The thermal stability of the polymer was examined by thermogravimetry (TG). A typical trace for the polymer is shown in Figure 3. The polymer 13 showed a $10 \%$ weight loss in air and nitrogen at $360^{\circ} \mathrm{C}$ and $390^{\circ} \mathrm{C}$, respectively.
We expected the difference in their properties owing to different regularity. However, no difference in the solubility and thermal stability among these polyamides can be detected. Pino et al. ${ }^{6}$ observed a similar behavior for the studies of the influence of constitutional isomerism on the physical propereties of polycondensate, and reported that unsubstituted polyamides might not be very suitable because strong effects brought about by extensive interchain $\mathrm{NH} \cdot$. OC bonds might mask subtle effects due to isomerism.

In summary, our studies indicate that the polyamide having a head-to-head or tail-to-tail sequence can be readily prepared by the direct polycondensation of symmetric monomer $\mathbf{2 b}$ with nonsymmetric monomer 5 by using the activating agent $\mathbf{1}$.

Acknowledgments. We thank Dr. R. Sato for the ${ }^{13} \mathrm{C}$ NMR measurements, $\mathrm{S}$. Kato for 
the technical assistance, and T. Takahashi for performing the elemental analyses. Financial support for this study by Tokuyama Science Foundation is gratefully acknowledged.

\section{REFERENCES}

1. M. Ueda, Yuki Gousei Kagaku Kyokaishi, 48, 144 (1990).
2. M. Ueda, M. Kakuta, T. Morosumi, and R. Sato, Polym. J., 23, 167 (1991).

3. M. Ueda, A. Kameyama, and K. Hashimoto, Macromolecules, 21, 19 (1988).

4. J. V. Brau and J. Seemann, Ber. Deutsch. Chem. Ges., 56, 2161 (1923).

5. M. Ueda, T. Morosumi, M. Kakuta, and R. Sato, Polym. J., 22, 733 (1990).

6. G. Xie, P. Pino, and G. P. Lorenzi, Macromolecules, 23, 2583 (1990). 